\title{
UMA BIOGRAFIA SOCIOLÓGICA
}

\author{
Thadeu de Jesus e Silva Filho
}

Aguiar, Ronaldo Conde (2000). O rebelde

esquecido: tempo, vida e obra de Manoel

Bomfim. Rio de Janeiro: Ed. Topbooks, 561p.

O livro de Ronaldo Conde Aguiar é oriundo da sua tese de doutorado, que recebeu o Prêmio de Melhor Tese de Doutorado no I Concurso Brasileiro CNPq-ANPOCS de Obras Científicas e Teses Universitárias em Ciências Sociais - Edição 1999.

Ronaldo Conde Aguiar intenta procurar nas circunstâncias e na trajetória pessoal de Manoel Bomfim respostas a duas ordens de perguntas: "como pôde ele construir suas reflexões e idéias, tão opostas e díspares das idéias e reflexões comuns de seu tempo e da sua classe social de origem? Quais as razões e motivos que o fizeram ser, enfim, um autor esquecido?", perguntas que fundamentam e orientam a feitura do livro - que o autor chamou de a "biografia sociológica" de Manoel Bomfim.

A expressão "biografia sociológica" aparece dezenove vezes no decorrer do livro, sendo que as dezesseis primeiras na Introdução e no Prólogo, dando a impressão mesmo de tratar-se de importante

Thadeu de Jesus e Silva Filho é sociólogo e antropólogo. Mestre em sociologia pela Universidade de Brasília. Atualmente, 2001, desenvolve tese de doutorado em Sociologia na mesma Universidade. 
conceito. A recorrência do seu emprego se dá pela defesa da pertinência de não haver "nenhuma dissensão entre um trabalho acadêmico, do qual se exige rigor no uso dos conceitos, e o prazer estético que uma biografia, como gênero literário, deve proporcionar aos leitores -e, de quebra, àquele que escreve"'. O significado de tal expressão ganha na quinta nota de rodapé a seguinte explicação: "Biografia - porque se centrou na vida de um personagem; sociológica - porque procurou, através da obra desse personagem, investigar o jogo conflituoso de interesses políticos e os traços marcantes de um campo intelectual e político numa determinada época histórica brasileira".

A Sociologia não é uma disciplina consensual nem no seu objeto, nem nos métodos, nem nas teorias e nem no valor do significado do "fazer sociológico" - lição esta aprendida da obra dos ditos clássicos: Karl Marx, Émile Durkheim, Max Weber, e por outros tantos autores. De modo que não é possível falar da Sociologia como única ou referir-se a ela e pretender univocidade e/ou consenso a seu respeito ${ }^{2}$. Ademais, donde a razão de chamar de sociológica a investigação do jogo conflituoso de interesses de um determinado campo intelectual? Não poderia esse proceder ser atinente aos estudos de História, de Ciência Política, de Antropologia ou de outra disciplina da grande área das Humanidades? Não poderia ser, então, uma biografia antropológica, uma biografia histórica (?) ou uma biografia política uma vez que os motivos elencados, mesmo que reivindicando autoridade de Charles Wright-Mills (em A Imaginação Sociológica), não perfazem nem de longe argumentação adequada para conferir a qualidade de sociológica a um trabalho? A recorrência e a insistência com que a expressão "biografia sociológica" é abordada e retomada revela uma preocupação muito grande em querer demonstrar a validade do esforço para a Sociologia. É uma espécie de querer provar/demonstrar que o esforço é bom e tem pertinência. O Prólogo todo expõe tal esforço, e isso é facilmente visto pelos aliados reunidos para tal demonstração: Benedetto Crocce, Paulo Rónai, Boaventura de Sousa Santos, Isaac Deutscher, Pierre Bourdieu, Didier Eribon, Friederich Nietzche, Sérgio Paulo Rouanet, Florestan Fernandes, José de Souza Martins, entre outros.

Nessa medida, a associação sugerida entre rigor (oriundo das características do trabalho acadêmico) e prazer (advindo das formas de gênero literário) parece ter dado menos ênfase ao rigor. Não está 
explícita, por exemplo (afora as descontinuidades já referidas), a concepção que se tem de política e, então, que fenômeno se quer observar; afinal, falar de política nos moldes de Hannah Arendt, por exemplo, é bem diferente de referir-se às querelas e quesilhas dos partidos políticos e de acusações entre intelectuais nos jornais.

O prazer, mais privilegiado que o rigor, continuou dando mostras de sua condição - fenômeno facilmente constatado a partir da percepção do forte tom coloquial utilizado no livro. Em primeira instância, a utilização de um modo mais casual de comunicação não significa necessariamente a inviabilização do texto e da sua compreensão, conforme demonstrou Gilberto Freyre principalmente em Casa-Grande \& Senzala, e Norbert Elias, em Mozart: sociologia de um gênio. Todavia, a construção de um texto nos moldes sociológicos, com todas as variações inerentes à Sociologia e que impedem mesmo a referência a ela como uma disciplina consensual, implica, inegociavelmente, num procedimento que prime por apresentar os argumentos de uma maneira tal que evite confusões de significado - e isso é questão de método. Com isso, o "fazer sociológico" significará produção de discursos cada vez mais livres de contradição. O livro apresenta algumas inconsistências no que respeita à esta especificidade argumentativa.

Por vezes, o leitor se depara com trechos cujo formato não é atinente nem a uma biografia, nem a um texto sociológico. Eis alguns desses fragmentos:

o comércio local era tosco, nada mais que três armazéns de secos e molhados, duas bodegas, duas padarias, uma loja de artefatos de couro, uma marcenaria e uma ferraria; (p. 52)

No dia seguinte, pela manhã, pai e filho caminharam, em silêncio, pelo Largo do Terreiro de Jesus, um vasto retângulo de chão batido e capim rente, em direção à Faculdade de Medicina. (...) Chegam. Sobem lentamente os poucos degraus da entrada lateral e penetram no corredor silencioso do prédio. São recebidos pelo secretário do estabelecimento, um baiano de meia idade, calvo e solícito; (p. 119)

Machado de Assis fez um discurso curto e pouco enfático, mas adequado ao seu estilo pessoal sóbrio. (...) Joaquim Nabuco, que falou em seguida, defendeu com bom humor o modelo da instituição 
que inauguravam naquela noite. Ao fim dos trabalhos foram servidos chás e biscoitos de araruta; (p. 203)

Concentrado no texto, Bomfim não percebeu de imediato a presença de Natividade, que trazia uma limonada, que o marido bebeu sofregamente; (p. 353)

Bomfim fez outra pausa. Levantou-se e, mais uma vez, caminhou pela sala. Aproximou-se da janela e verificou que as nuvens iam, aos poucos, se dissipando. Sentou-se novamente à mesa. Colocou uma pena nova na caneta, mergulhou-a no tinteiro e retomou (...); (p. 354)

Chovia. Manoel Bomfim desceu do landau, atravessou apressadamente a rua da Lampadosa (...) e penetrou no prédio do Instituto Nacional de Música. No saguão, encontrou-se com Coelho Neto, Medeiros e Albuquerque, Olavo Bilac e Alcindo Guanabara, que o aguardavam, ansiosos: 'Chegou, afinal!' - 'Já não era sem tempo!' - 'Estávamos preocupados' - 'Que chuva, seo Bomfim!'. Havia no recinto umas trinta a quarenta pessoas, muitas do sexo feminino. (p. 359)

A sensação é de estar diante de uma narrativa ficcional, onde os diálogos, as situações de encontro interpessoal, as paisagens naturais e o ambiente foram claramente criados pela imaginação ${ }^{3}$ e assim o foram sob o argumento de que "a forma clássica de redação de uma tese acadêmica, (...) assume, quase sempre, 'o ranço de fastidiosos relatórios" " 4 . Mas se é ou se se pretende de caráter sociológico, é mister que se apresente a origem de tais dados. Se não, do que se trata: de um romance biográfico-sociológico ou de outro neologismo? As páginas que vão da 123 até a 126 perfazem um longo trecho da situação acima citada.

Os ambientes criados por diálogos imaginados fazem parte de um ambiente maior onde são expostas a vida e a obra de Manoel Bomfim: é o que foi chamado no subtítulo do livro de o tempo. Apresentando estes três aspectos conjuntamente e entendendo o tempo como sinônimo do que Karl Mannheim chamou de constelação ${ }^{5}$, o texto ficou, óbvia e inevitavelmente, eivado de referências a contextos históricos. Estes, apresentados principalmente como ambiente, intentaram explicitar os acontecimentos da vida política do Brasil contemporâneos a Manoel Bomfim como circunstâncias com as quais ele se deparou durante sua vida e que podem ter influenciado o teor da sua produção. 
É o caso das citadas crise do encilhamento, promulgação da primeira constituição republicana, dissolução do Congresso Nacional, renúncia de Deodoro da Fonseca, revolução federalista e revolta das esquadras, discussões a respeito da política indigenista, fundação da Academia Brasileira de Letras, etc.

Todavia, o tempo apresentado é composto de idéias e interpretações cristalizadas a respeito de tais acontecimentos, onde os eventos políticos citados no livro reproduzem e transcrevem as idéias do que se entende por História do Brasil da época da vida de Manoel Bomfim. Nessa medida, é uma representação do senso comum. Prova disso são os autores tomados como referência: Caio Prado Jr., Boris Fausto, Nelson Werneck Sodré, Gilberto Dimenstein, Celso Furtado, Renato Ortiz, Wilson Martins, Dante Moreira Leite, e outros. Não privilegiando a busca por leituras e interpretações mais inovadoras para o tempo, as narrativas são tradicionais e possuem um tom quase como de "verdades indiscutíveis e suficientes" - como é o caso da interpretação da abolição da escravidão e da instauração da República citados à página 136. Acontece algo muito semelhante na exposição da influência do positivismo que se instalou no Brasil. Não é dito uma vez sequer que positivismos aqui chegaram, quais eram seus traços característicos e suas diferenças, qual deles foi mais aceito e os motivos pelos quais isso veio a acontecer.

Assim, O rebelde esquecido: tempo, vida e obra de Manoel Bomfim não é uma história das idéias, nem a discussão das idéias do biografado - algo como Religião e Modernidade em Habermas ${ }^{6}$-, nem a sistematização do conteúdo das discussões de Manoel Bomfim com alguns pensadores de então, não apresentando mesmo a articulação das idéias e dos debates daí decorrentes. $\mathrm{O}$ que se percebe muito facilmente é a presença marcante de nomes, de pessoas e de alguns movimentos, mas não de idéias, conforme sugerem os objetivos do livro, de modo que a "biografia sociológica" de Manoel Bomfim ultrapassa o ambiente apenas quando é apresentado o foco da narrativa: neste caso, o contato entre uma pessoa e um ente (outra pessoa, uma instituição, um acontecimento). Isso é o que há de diferente, o resto é moldura cristalizada e argumentação comum.

O livro apresenta com muita ênfase a educação como um grande tema e, ainda, como o grande pilar do projeto nacional de Manoel Bomfim. São feitas menções a respeito da sua importância para 
o biografado não apenas nos textos por ele escritos mas, de maneira muito significativa, ao explicitar os cargos públicos e funções por ele ocupados relacionados à educação. Foi o caso da direção do Pedagogium (espécie de museu pedagógico nacional, inicialmente idéia de Rui Barbosa no parecer emitido em 1882 acerca do projeto de reforma de ensino de Rodolfo Dantas), da fundação e direção do mensário Educação e Ensino e da criação da revista Pedagógica.

Ao mesmo tempo em que a educação é enfatizada, falta a explicitação de duas idéias fundamentais para Manoel Bomfim a respeito de um projeto nacional por ele tecido, principalmente a partir da idéia de que é possível superar os males de origem que assolam o Brasil. Tal superação se daria a partir da implementação de uma política de educação para o povo, de especial modo, a educação primária, acompanhada de fomento da ciência e de uma ética do trabalho. Este é o exemplo mais significativo da falta de tratamento substantivo da obra de Manoel Bomfim, cujo lugar foi ocupado pela descrição do tempo sem, contudo, demonstrar como e por que os acontecimentos componentes do ambiente influenciaram ou não na composição da obra - o máximo apresentado nesse sentido foram as razões elencadas ao final para o seu "esquecimento". Os aspectos substantivos, embora expostos, sempre foram apresentados como opiniões fortes e como posicionamentos pessoais do autor, mas não de molde a expor sistematicamente seu pensamento a respeito de um certo tema e seu projeto nacional, dando a sensação esporádica de ser não só um rebelde esquecido mas um herói, acima do bem e do mal diante de várias agruras: prisão dos amigos, morte de parentes, possibilidade de prisão, ...

Com isso, o livro apresenta o que o mundo ocidental elegeu como os grandes temas da vida de um homem: sua terra natal, o sucesso do pai e o sonho deste para com seu filho, o forte e inspirador silêncio da mãe, a briga entre pai e filho para este seguir o "próprio caminho", a formação profissional, a vida amorosa - as aventuras sexuais entretidas, as traições sofridas, o grande amor encontrado, as amantes -, as realizações profissionais, a maneira sempre peculiar de crer em Deus, a morte dos parentes e o modo como o fim chegou para si.

Enfim, esses comentários são indicações de falhas que aos olhos do crítico pareceram importantes ressaltar, no espírito do melhor debate acadêmico. Porém, não se pense que $O$ rebelde esquecido: tempo, vida e obra de Manoel Bomfim seja um livro a ser descartado. Pelo 
contrário, além de ser um livro bastante agradável de ler, juntamente com a apresentação muito oportuna, válida e de grande contribuição da apresentação da obra completa de Manoel Bomfim ao final do livro, que são inegáveis qualidades, trata-se do esforço de recuperar um autor, Manoel Bomfim, injustamente esquecido por grande parte do pensamento brasileiro.

\section{Notas}

1 Página 22.

2 A esse respeito, ver Thadeu de Jesus e Silva Filho, "As múltiplas singularidades do fazer sociológico, ou da necessária cautela metodológica em sociologia”. Série Sociológica, n. ${ }^{\circ} 186$, Departamento de Sociologia, Universidade de Brasília, 2001.

3 Adequadamente, o último capítulo é intitulado de "epílogo", e um dicionário dos nomes dos escritores, dos poetas e dos jornalistas citados tem a denominação de "elenco", referências condizentes com o desenvolvimento da trama.

4 Página 22.

5 Karl Mannheim "O problema de uma sociologia do conhecimento" in Bertelli, A., Palmeira, M., Velho, O. Sociologia do Conhecimento. Rio de Janeiro: Zahar Editores, 1974, segunda edição.

6 Luiz Bernardo Leite Araújo. São Paulo: Edições Loyola, 1996. 